\title{
Study on the Spatial Form of Marginal Space of the Street and Crowd Behavior -Take Tanhualin Historic District as an example
}

\author{
Shunzhe Pei ${ }^{1, a^{*}}$ \\ ${ }^{1}$ School of Civil Engineering and Architecture, Wuhan University of Technology, Hongshan District, Wuhan, China
}

\begin{abstract}
While people tend to overlook marginal space, it is the most important space for communication and integration. This paper took the historic districts of Tanhualin as the subject to explore the spatial elements, spatial characteristics and crowd behaviors of different types of marginal space from the perspective of typology. Based on the number of active users and the space utilization rate, we evaluated the marginal space using image data analysis. This paper explored the design of marginal space, providing references on the rational development of marginal space of urban blocks and improvement of marginal space.
\end{abstract}

\section{Background-Concept of Marginal Space}

\subsection{Marginal space}

The term "marginal space" first appeared in the field of ecology, an ecotone or a transitional area between two ecosystems [1]. In 1985, the SCOPE/MAB working group defined it as an interface between materials of different structures and functions in the ecosystem. In 1986, Foreman defined the landscape ecotone as heterogeneous landscape between different adjacent homogeneous landscapes, which controls the movement of biological and non-biological elements.

Later, the concept of marginal space was introduced into the field of urban design [2]. Kevin Lynch wrote in Urban Image: "Margin (boundary) is a linear element among the five major elements of a city, which is the dividing line between two regions and the linear interruption of continuous space. But they can also penetrate into each other and distinguish between regions at the same time. It can also be a joint, where two areas along the line are interrelated and connected together."

Marginal space is formed by the intersection of two areas or spaces with different functions and spatial textures. Differences in the attributes of the peripheral areas of marginal space lead to the distinct features of marginal space, characterized by heterogeneity, intermediary, publicity and hierarchy.

\subsection{Characteristics of marginal space}

(1) Heterogeneity: Heterogeneity refers to the mutation on the regional boundary. Because of heterogeneity, marginal space can gather energy from different regions and thereby be enriched, which is manifested by the fuzziness of space

\footnotetext{
"Corresponding author: ${ }^{\mathrm{a} 1304163934 @ q q . c o m}$
}

and the diversity of activities.

(2) Intermediating property: The intermediating property refers not only to the central position of marginal space in several spaces or regions, but also the semipermeable membrane in biology, which allows the adjacent spaces to continuously exchange materials and information. The intermediating property endows marginal space with inclusive abilities to meet people's various needs.

(3) Public property: Although marginal space divides the space into different sectors, it also plays the role of connecting adjacent regions. As the marginal space is occupied by the adjacent space at the same time, it is also the place where various people take activities. Therefore, the marginal space is diversified and serves as an excellent carrier of public activities.

(4) Hierarchy: Like many public spaces, different kinds of crowd activities take place here. Therefore, the marginal space is hierarchical, including spatial components of different scales such as walls, ladders, green plants and other facilities.

\subsection{Relationship between adjacent spaces}

Marginal spaces are formed by the interaction between adjacent spaces, which determine the spatial characteristics and forms of the marginal space ${ }^{[3]}$. In general, there are the following types of interactions (Figure 1):

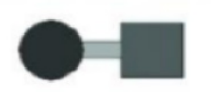

coupling

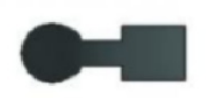

transition

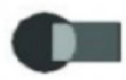

lamination

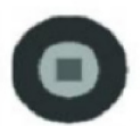

shielding
Figure 1. Formation of Marginal Space 
(1) Adjacent spaces are independent and connected by the marginal space;

(2) The adjacent spaces are not completely separate, but partially integrated by the marginal space as the transition;

(3) The marginal space serves as the overlap of the adjacent spaces, belonging to both spaces;

(4) The adjacent spaces are in an enclosing relationship, with the marginal space serving as the dividing line.

\section{General Information of the Tanhualin Historic District}

\subsection{Site of Survey}

Tanhualin (as shown in Figure 2) is located in the west of Wuchang District of Wuhan in Hubei Province, between the northern foot of Garden Hillsare and the southern foot of Crab Cape. The profound culture and history of Tanhualin endows this region with diverse spatial forms. Residents from all walks of life live in the block, including local vendors, students from the University of Traditional Chinese Medicine, middle-aged and elderly people, tourists and so on. People from different walks of life have different behaviors. The interactions between people's behavior and the space form a unique scenery, and provide a place for outdoor activities to meet people's daily needs.

\subsection{Features of the historic district}

(1) A mixed community thanks to its profound history, which harbors a number of traditional industries and business in the block, making it a place suitable for people to live in.

(2) The blending of old and new buildings, making it special in the metropolitan.

(3) There are various living spaces with different standards and scales to meet the needs of people, including local residents, shop owners and students.

(4) A variety of historic relics.

(5) The residents in the block have been renovating the

place to meet their daily needs in the limited space, which is based on well-prepared design rather than random construction.

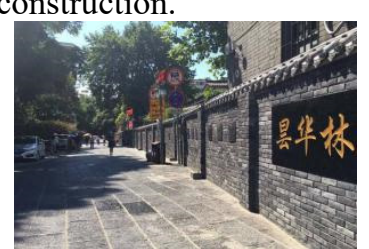

Figure 2. Photograph of Tanhualin

\section{Morphological Composition of Marginal Space in Tanhualin Historical District}

The historical district of Tanhualin consists of three parts: the main street of Tanhualin, residential area near Desheng Bridge and residential area in the mountain. This paper mainly studied the main street of Tanhualin. The following figure presents the schematic diagram of the location of the major nodes of marginal space (as shown in Figure 3), and several typical nodes were involved in the study.

\subsection{Morphological composition of marginal space}

The main street is the main entrance to buildings on both sides of the street in Tanhualin. There are many kinds of buildings on both sides of the street in Tanhualin block, including shops, dormitories, exhibition halls, residential areas, etc., thus creating different marginal spaces. This part of public space emphasizes more on the transition and symbolic implications of spaces. The change of ground material implies the transformation of space, while the horizontal and vertical interfaces indicate the relationship between the space and architecture. Also, public facilities add vitality to this area. The marginal spaces in the main street include point-like space, linear space and planar space.

Table 1. Analysis of Marginal Space of the Main Street of Tanhuali

\begin{tabular}{|c|c|c|c|c|c|}
\hline $\begin{array}{l}\text { Marginal } \\
\text { Space }\end{array}$ & Name & Photograph & Spatial Element & Spatial Feature & Crowd Behavior \\
\hline \multirow[t]{2}{*}{$\begin{array}{l}\text { Point-like } \\
\text { Space }\end{array}$} & $\begin{array}{l}\text { 1. The grey } \\
\text { space at the } \\
\text { entrance to the } \\
\text { building }\end{array}$ & 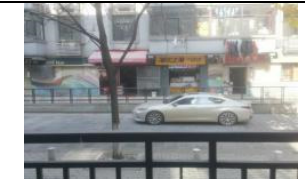 & $\begin{array}{l}\text { Sunshade ceiling, glass } \\
\text { window and glass door, } \\
\text { and green plants at the } \\
\text { entrance to the building }\end{array}$ & $\begin{array}{l}\text { The ceiling gives people a } \\
\text { sense of security, while the } \\
\text { distinct facade design of each } \\
\text { store serves as its logo }\end{array}$ & $\begin{array}{lrr}\begin{array}{l}\text { Passing } \\
\text { stopping }\end{array} & \text { or } \\
\text { appreciate } & \text { to } \\
\text { scene. } & & \text { the } \\
& & \end{array}$ \\
\hline & $\begin{array}{l}2.24 \mathrm{~h} \\
\text { Community } \\
\text { Library }\end{array}$ & & $\begin{array}{l}\text { Integrated device, steel } \\
\text { frame ceiling, semi- } \\
\text { indoor bookshelf, grey } \\
\text { space wooden seat }\end{array}$ & $\begin{array}{l}\text { As a public space, the sidewalk } \\
\text { can attract pedestrians. } \\
\text { However, this place is too wide } \\
\text { open for reading. }\end{array}$ & $\begin{array}{l}\text { Reading, chatting, } \\
\text { resting and } \\
\text { borrowing books }\end{array}$ \\
\hline $\begin{array}{l}\text { Linear } \\
\text { Space }\end{array}$ & $\begin{array}{l}\text { 3.Corridor } \\
\text { next to student } \\
\text { dormitory }\end{array}$ & & $\begin{array}{l}\text { Marble steps, iron } \\
\text { railings and L-shaped } \\
\text { stone pillars }\end{array}$ & $\begin{array}{l}\text { The height difference gives the } \\
\text { corridor a higher level of } \\
\text { privacy, allowing a greater } \\
\text { variety of behaviors }\end{array}$ & $\begin{array}{l}\text { Passing by, jogging, } \\
\text { chatting, reading, } \\
\text { and playing games }\end{array}$ \\
\hline
\end{tabular}




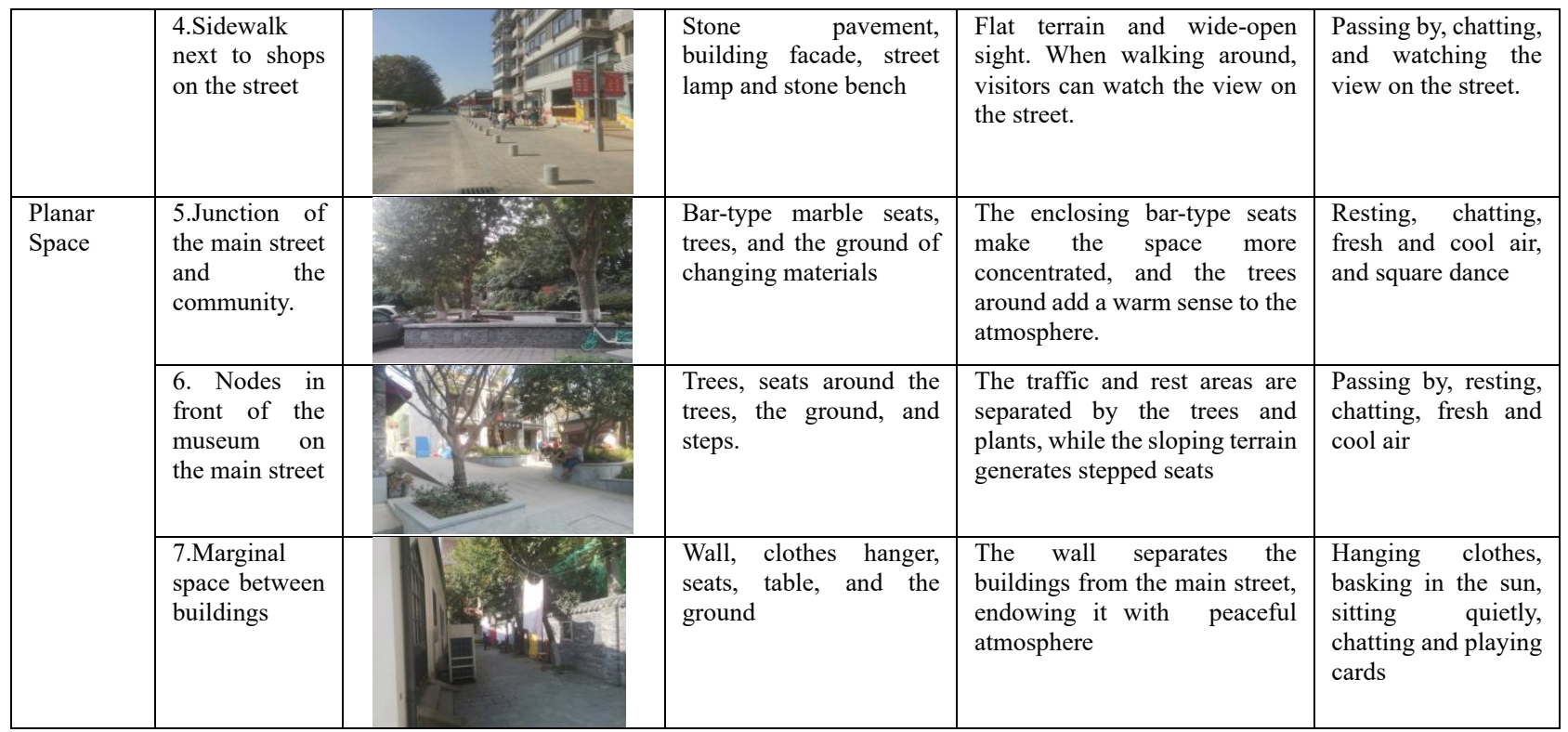

\subsubsection{Point-like marginal space}

There are two kinds of point-like marginal spaces in Tanhualin: The gray space at the entrance of buildings and point-like infrastructure.

The entrance space of a building is defined by horizontal elements such as ceiling (Figure 4). As it is a public building, it boasts both public attributes and privacy. The entrance facade and green plants as the decoration at the entrance form the symbolic marginal space of each shop, which plays an important role in creating the cognitive atmosphere of the place.

The typical point-like infrastructure in the block is the 24h library in the photograph (as shown in Figure 5). Infrastructure plays an important role in stimulating the vitality of marginal space. Building a library as an accessorial building on the street not only provides residents a place for reading, but also serves as a leisure center for visitors. However, there is still room of improvement for the location and form of the accessorial building. As the library is too close to the entrance of nearby buildings, it could affect traffic. As a place for reading, the lack of surrounding space and too wide-open sight are not conducive to reading.

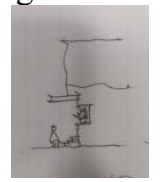

Figure

4.

Entrance

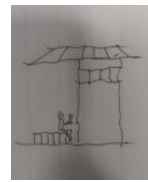

Figure 5. $24 \mathrm{~h}$ Library

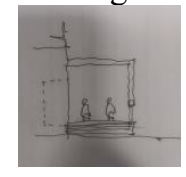

Figure6. Marginal Corridor of the Dormitory

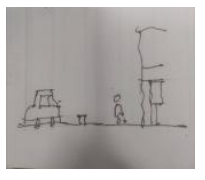

Figure 7.

Sidewalk along Buildings

\subsubsection{Linear Marginal Space}

Linear marginal space mainly refers to sidewalks beside buildings, with the function of traffic and communication
${ }^{[5]}$. Reasonable spatial distance is an important indicator in the evaluation of linear spatial space (as shown in Figure $8)$.

\begin{tabular}{ccc}
\hline type & Space distance & effect \\
\hline close distance & $0-45 \mathrm{~cm}$ & Express strong feelings \\
personal distance & $45-130 \mathrm{~m}$ & talk to close friends \\
social distance & $130-375 \mathrm{~cm}$ & Daily conversations between friends, colleagues \\
pub1ic distance & $>375 \mathrm{~cm}$ & A meeting or speech of one-way comnunication \\
\hline
\end{tabular}

Figure 8. Relation between Spatial Distance and People's Feelings

Linear marginal space mainly refers to the pedestrian walkways between buildings and main streets, which are divided into two types:

The first type is a narrow linear corridor with top surface (as shown in Figure 6), with most sections around $2500 \mathrm{~mm}$ in width, and the distance between people is kept within personal distance and intimate distance. The linear marginal space is close to the student dormitory, with its bottom above the ground of the main street and its side surrounded by railings. Both the height difference and the fence limit the extension of the marginal space, and the whole linear corridor is allowed to retract and extend. The narrow section is mainly for pedestrians to pass through, while some areas are recessed into the building and serve as a leisure place, where students living nearby can study and pedestrians have chatting. Because of the limitations, this area has a greater level privacy, suitable for students or pedestrians to have independent activities.

The second type is a wide sidewalk without top surface (as shown in Figure 7), with most sections $4000 \mathrm{~mm}$ in width, and the distance between people is mostly social distance and public distance. The linear marginal space is close to walls or buildings, with no twists or turns in the route, thus creating wide-open sight. Students' activities on the playground are visible through the campus fence near the wall of Hubei University of Chinese Medicine, adding visual vitality to the street. This space is more public than private, which is suitable for tourists to walk around, enjoy the scenery and experience the culture of the 
blocks.

\subsubsection{Planar marginal space}

Although the planar marginal space is a kind of marginal space, it is different from other types of marginal space because it is far more enriched and can meet people' needs for various activities. The planar marginal space mainly consists of spatial nodes at the junction of blocks, surrounding communities, shops and other land, and some planar spaces are produced by building concessions from the main street. Three typical planar marginal spaces are selected and analyzed below.

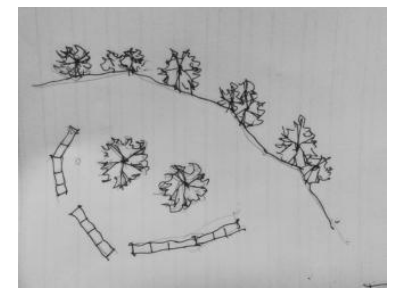

Figure9. Schematic Diagram Communities of Entrance Nodes to

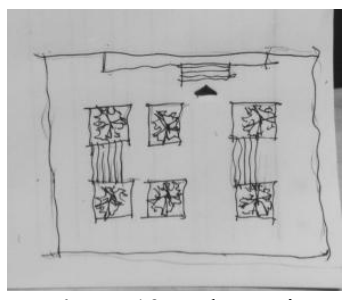

Figure10. Schematic Diagram of Entrance Nodes to Buildings
The first is the spatial node at the junction of the east end of Tanhualin Main Street and the residential area (as shown in Figure 9). This space is mainly enclosed by a series of bar-type marble seats to generate a plane shape of the space, and the trees enhance the sense of shelter. This space has multiple functions and can accommodate various crowd activities. In the morning and afternoon, residents and tourists can sit here and have a rest. In the evening, it serves as place for square dance for local residents.

The second is the spatial node formed by the concession of an exhibition hall from the main street (as shown in Figure 10). This space is divided by trees and plants, with multiple functions such as transportation, communication and sight-seeing. Meanwhile, the height difference is used to generate stepped seats for rest.

The third is the area between the walls of two buildings on the main street, which is completely different from the lively atmosphere of the main street as they are separated by the walls. Local residents placed drying racks, seats and tables here, bringing freedom and peace to this place. Residents hang clothes here in the morning, and chat and play cards in the afternoon.

\subsection{Analysis of crowd behavior in the marginal space}

To further explore the relationship between the form of the marginal space and people's behavior, statistics and data analysis are made on the number of users of each marginal space in different time periods.

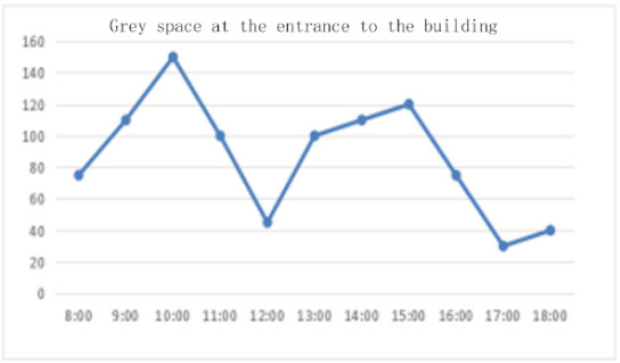

Figure 11. Statistics of People Utilizing Grey Space at the Entrance to the Building

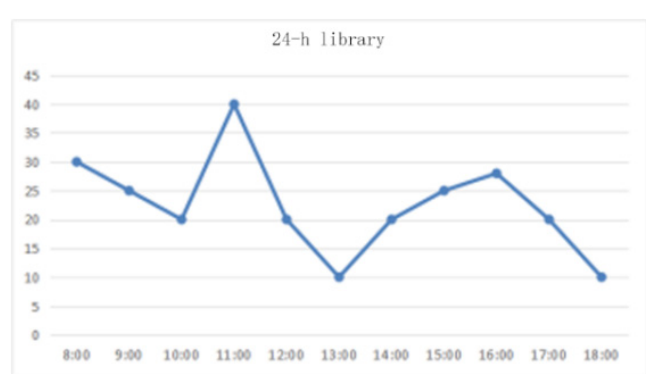

Figure 12. 24h Statistics of People Utilizing Library

\subsubsection{Grey space at the entrance to the building}

According to the statistics (as shown in Figure 11), the number of users is on a upward trend from 8: 00 to 10: 00 and on a downward trend from 10: 00 to 12: 00. From 12: 00 to $17: 00$, the number of users is on the rise, which peaks at 151 at 10:00 and hits the bottom of 32 at 17: 00. The fluctuation is mainly caused by the number of tourists.

\subsubsection{4h small library}

According to the statistics (as shown in Figure 12), the number of users is on the rise from 8: 00 to 10: 00 , and shows a downward trend from 10: 00 to 11: 00 , with the largest decline from 11: 00 to 13: 00 before a slow increase from 13: 00 to 16: 00 , followed by a decline from 16: 00 to 18: 00 . The number peaks at 41 at 11:00, and hits the bottom of 10 at 13:00. There are few people utilizing the library, with a low space utilization rate.

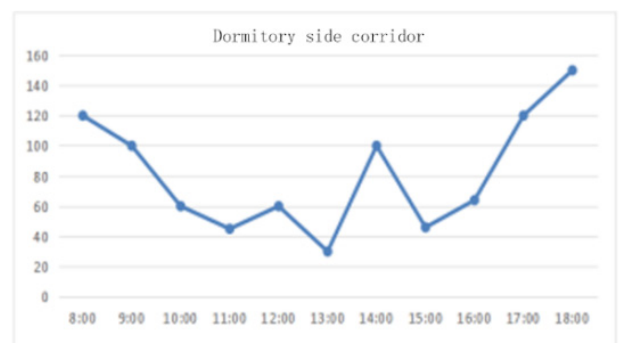

Figure 13. Statistics of the Number of People on the Corridor Next to Dormitory 


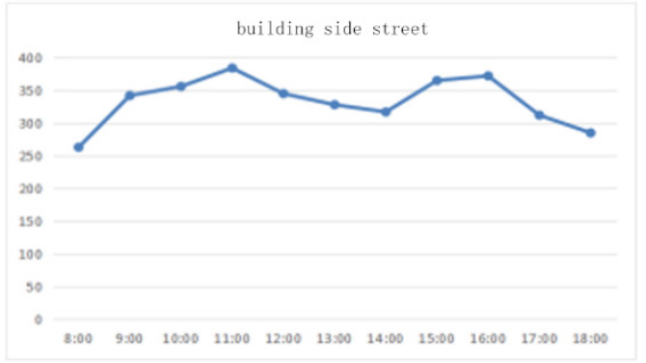

Figure 14. Statistics of the Number of People on the Sidewalk beside Buildings

\subsubsection{Corridor next to the dormitory}

According to the statistics (as shown in Figure 13), the number of users generally shows a rising trend before declining, and picks up at 14:00. The number of users peaks in the morning, evening and around 14:00, which is greatly influenced by the routine of students.

\subsubsection{Sidewalk beside buildings}

According to the statistics (as shown in Figure 14), there is no significant difference in the number of users in a day, which is generally kept within a certain range. The number of users averages 334 between 8: 00 and 18: 00 .

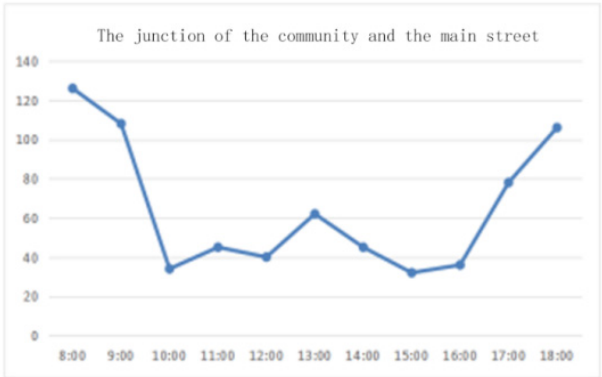

Figure 15. Statistics of the Number of People at the Junction of Community and the Main Street

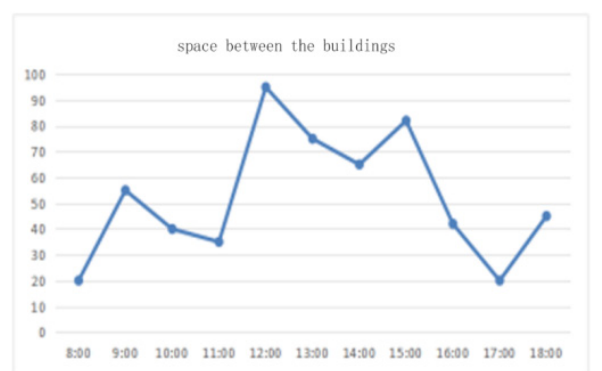

Figure 16. Statistics of the Number of People in the Marginal Space between Buildings

\subsubsection{Spatial nodes at the junction of community and the main street}

According to the statistics (as shown in Figure 15), there are more users in the morning and evening while there are fewer users in the rest of the day with little fluctuation. The number peaks at 128 at 8:00, and hits the bottom of 36 at 10:00. The main users of this space are community residents, who come here to buy cooking materials and rest during square dance.

\subsubsection{Space between buildings}

According to the statistics (as shown in Figure 16), the number of people peaks in the afternoon while there are fewer people in the morning and evening. The number peaks at 95 at 12:00, and hits the bottom of 20 at 17:00. The main users of this space include local residents, who chat, play cards and dry their clothes here after dinner.

According to the experiment, the main street of Tanhualin is mainly for tourists, local residents and students. The above data analyzes how the utilization rate of various marginal spaces varies with time, providing references to the further exploration of marginal spaces that meet people's needs and facilitate communication.

\section{Conclusion}

The decline of metropolitans described in Life and Death of American Big Cities highlights the necessity to integrate the diversity of cities with the traditional spaces to rejuvenate modern cities. Therefore, by studying the main street of Tanhualin, this paper actively explored how to create a marginal space suitable for communication and life ${ }^{[6]}$.

The study on the spatial form and characteristics of the marginal space of Tanhualin historical district offers references to the rational development of urban space in the future, and create marginal spaces that fits well with the surroundings. The marginal space could guide the integration of city, traditional blocks and natural environment, and promote the harmonious coexistence between man and nature.

\section{References}

1. Xing,Z.,Wang,Q.(2005)On marginal space.New buildings, 5:82-84.

2. Lynch,K.(2001)the image of the city.Huaxia Publishing House,Beijing.

3. Xiang Lanlin, Zhu Keqin. Morphological composition of marginal space in external space. Sichuan architectural science research, 2009 (12): 248-253.

4. Chen Wenjia, Zhu Chunyang, Zhou Yi. Study on the edge space form of urban life block: a case study of Tanhualin historical life block. Central China architecture, 2014

5. Lu Yuan Yixin. Aesthetics of streets. Beijing: China Construction Industry Press, 1999

6. Jacobs, Jane. The life and death of American big cities. Trans. Jin Hengshan. Nanjing: Yilin publishing house, 2005 